\title{
Meaningfulness, associative reaction time, recognition latency, and pronunciability in free recall
}

\author{
RONALD LEY and JURGEN KARKER \\ State University of New York, Albany, New York 12222
}

\begin{abstract}
This study extended the validity assessment of the 319 CVCVC words and paralogs measured for meaningfulness (m'-scaled-rated meaningfulness) by Locascio and Ley (1972b). Thirty-six subjects were presented three lists of 12 units each and instructed to recall these units after presentation of each list. Meaningfulness correlated significantly with recall frequency, $r(34)=.71, p<.001$. The secondary purposes were (a) to determine correlations between other assessment measures, viz., associative reaction time, pronunciability, and recognition latency, with recallability; and (b) to determine the intercorrelations among these measures. Consistent with Ley and Locascio's recognition-recall hypothesis, associative reaction time correlated with recallability to a greater degree $(r=-.56)$ than recognition latency $(\mathrm{r}=-.23)$ or pronunciability $(\mathrm{r}=-.41)$. The intercorrelations among all assessment values were significant $(p<.005)$ and relatively large.
\end{abstract}

The primary purpose of the present study was to extend the assessment of the validity of the 319 CVCVC words and paralogs measured for meaningfulness ( $\mathrm{m}^{\prime}$-scaled-rated meaningfulness) by Locascio and Ley (1972b). Although Locascio and Ley (1972a) reported the results of an experiment which provided some construct validation of their measurements (i.e., a sample of high-M CVCVCs was recalled more frequently than a sample of low-M CVCVCs under each of four different study modes), their results were based on conditions in which the treatments were individually administered to each subject. In the present study a stratified sample of CVCVCs representing the entire distribution of meaningfulness $\left(\mathrm{m}^{\prime}\right)$ was selected and used in a free recall study under group administration conditions. On the basis of the results of previous studies of the effect of meaningfulness in verbal learning, it was expected that the scaled-rated meaningfulness values of the CVCVCs of the present study should correlate significantly with the frequency of their recallability.

Since the associative reaction times (RT) of these same 319 CVCVCs had already been measured by Taylor and Kimble (1967) and since the units were subsequently assessed for recognition latency (RL) by Ley (Note 1) and for pronunciability (PR) by Ley and Karker (1974), the secondary purpose of the present study was (a) to determine the correlations between these measures and recallability, and (b) to determine the intercorrelations among the measures (viz., $\mathrm{m}^{\prime}, \mathrm{RT}$, $R L$, and PR). An issue of theoretical interest was cen-

This research was supported in part by a State University of New York Research Foundation grant-in-aid to the first author. Requests for reprints should be sent to Ronald Ley, State University of New York at Albany, 1400 Washington Avenue, Albany, New York 12222. tered on the differences in the predictive strengths of associative reaction time, recognition latency, and pronunciability with respect to recallability. On the basis of Ley and Locascio's (1970b) hypothesis that (a) recognition and recall are different memory processes and (b) the amount of time required to make an association (RT) to a perceptually encoded unit determines the probability of recall of the unit, it was expected that associative reaction time should correlate with recall frequency to a greater degree than either recognition latency or pronunciability.

\section{METHOD}

\section{Subjects}

The subjects were 36 undergraduate students at the State University of New York at Albany, naive with respect to prior experience in verbal learning studies.

\footnotetext{
Materials

The materials were a stratified-random sample of $36 \mathrm{CVCVC}$ verbal units selected from the list of 319 words and paralogs assessed for scaled-rated meaningfulness $\left(\mathrm{m}^{\prime}\right)$ by Locascio and Ley (1972b), associative reaction time by Taylor and Kimble (1967), and pronunciability by Ley and Karker (1974). The sample was stratified with respect to scaled-rated meaningfulness by means of ordering the 319 units on a continuum from lowest meaningfulness to highest meaningfulness. The entire list was then subdivided into 12 sublists, the first 5 of which contained 26 units and the remaining 7,27 units. The first sublist contained the 26 lowest meaningfulness units, the second sublist, the next 26 units lowest in meaningfulness, and so forth through to the 12 th sublist, which contained the 27 highest meaningfulness units. From within each of the 12 sublists, three units were randomly selected and each assigned to one of the three lists, thus creating three lists, each of which contained one unit from each sublist.

Since each subject was presented with all of the three lists, a possible order effect was controlled for by presenting each list in the first, second, and third position an equal number of times. Within each list, the order of presentation of the units was randomly determined.
} 


\section{Procedure}

Subjects were tested in groups of six. They were seated at individual desk chairs facing a movie projection screen upon which slides containing the verbal units were shown via a Kodak Carousel slide projector. The subjects were instructed to read silently a standard set of instructions which outlined the free recall task. The subjects were told that they would be shown three lists of verbal units, all of which would share the same structural characteristics of CVCVC letter order. Following the instructions, a practice list of four CVCVCs was presented at a 4-sec presentation rate. Following the practice list, each of the three test lists of 12 CVCVCs each was presented at a 4-sec rate, with a 60 -sec interlist interval during which subjects were instructed to write the words of the list they had just seen. The criterion measure was the total number of units of all three lists correctly recalled.

\section{RESULTS AND DISCUSSION}

The product-moment correlation coefficients among the CVCVC assessment values ( $m^{\prime}, R T, R L$, and PR) and recall frequency scores are given in Table 1 . With respect to the primary purpose of the present study, meaningfulness $\left(\mathrm{m}^{\prime}\right)$ was found to be strongly correlated with Recall Frequency, $r(34)=.71, p<.001$, thus providing additional evidence for the validity of the scaled-rated meaningfulness measures of Locascio and Ley's list of 319 CVCVCs.

With respect to the secondary purpose of the present study, the intercorrelations among all the assessment values were significant $(p<.005)$ and relatively large. The correlations between meaningfulness $\left(\mathrm{m}^{\prime}\right)$ and associative reaction time $(\mathrm{RT})(\mathrm{r}=-.77)$ and meaningfulness $\left(\mathrm{m}^{\prime}\right)$ and pronunciability $(\mathrm{PR})(\mathrm{r}=-.75)$ were large and, more importantly, very close in agreement with the correlations between associative frequency $(\mathrm{Mn})$ and associative reaction time $(\mathrm{r}=-.80)$ and meaningfulness and pronunciability $(\mathrm{r}=.83)$ reported by Ley and Locascio (1970a). Furthermore, the correlation between associative reaction time and pronunciability of the present study is the same as that reported by Ley and

Table 1

Product-Moment Correlation Coefficients Among the Four Assessment Measures and Recall Frequency $(\mathrm{df}=34)$

\begin{tabular}{ccrrr}
\hline $\begin{array}{c}\text { Assessment } \\
\text { Measures }\end{array}$ & RT & PR & RL & Recall \\
\hline $\mathrm{m}^{\prime}$ & -.77 & -.75 & -.57 & .71 \\
$\mathrm{RT}$ & & .80 & .59 & -.56 \\
$\mathrm{PR}$ & & & .77 & -.41 \\
$\mathrm{RL}$ & & & & -.23 \\
\hline
\end{tabular}

$r=.27, p=.05$

$r=.33, p=.025$

$r=.42, p=.005$
Locascio (1970a), viz., $r=.80$, thus attesting to the reliability of the pronunciability rating method provided by Underwood and Schulz (1960).

Meaningfulness $\left(\mathrm{m}^{\prime}\right)$ aside, the best predictor of Recall Frequency was associative reaction time (RT) $(r=-.56)$ and, consistent with the predictions based on Ley and Locascio's (1970b) recognition-recall hypothesis, the correlation between associative reaction time and Recall $(r=-.56)$ was significantly greater than the correlation between recognition latency (RL) and Recall $(r=-.23)$. Furthermore, although recognition latency and pronunciability (PR) were highly correlated $(r=.77)$, the correlation between recognition latency and Recall was not significant $(\mathrm{r}=-.23, \mathrm{p}>$ $.05)$, whereas pronunciability was significantly correlated with Recall $(\mathrm{r}=-.41, \mathrm{p}<.025)$.

It should be noted that comparisons between meaningfulness and the other assessment measures as predictors of recall frequency were omitted because the sample of CVCVCs upon which the correlations were based was stratified with respect to meaningfulness.

\section{REFERENCE NOTE}

1. Ley, R. Unpublished study. State University of New York at Albany, 1972.

\section{REFERENCES}

Ley, R., \& KARKer, J. Pronunciability ratings of 319 CVCVC words and paralogs previously assessed for meaningfulness and associative reaction time. Bulletin of the Psychonomic Society, 1974, 3, 421-424.

LEY, R., \& Locascio, D. Associative reaction time and meaningfulness of CVCVC response terms in pairedassociate learning. Journal of Experimental Psychology, $1970,83,445-450$. (a)

LEY, R., \& LoCASCIO, D. Effects of associative reaction time and meaningfulness of stimulus terms in forward and backward paired-associate learning. Psychological Reports, 1970, 27, 867-873. (b)

Locascio, D., \& LEY, R. Associative reaction time, meaningfulness, and mode of study in free recall. Journal of Experimental Psychology, 1972, 95, 460-462. (a)

LoCASCIO, D., \& LEY, R. Scaled-rated meaningfulness of 319 CVCVC words and paralogs previously assessed for associative reaction time. Journal of Verbal Learning and Verbal Behavior, 1972, 11, 243-250. (b)

Taylor, J., \& Kimble, G. Association value of 320 words and paralogs. Journal of Verbal Learning and Verbal Behavior, 1967, 6, 744-752.

UNDERWOOD, B. J., \& Schulz, R. W. Meaningfulness and verbal learning. Chicago: Lippincott, 1960.

(Received for publication April 7, 1976.) 